Damman, O.C., Boer, D. de, Hendriks, M., Meuwissen, L.E., Rademakers, J., Delnoij, D.M.J., Groenewegen, P.P. Differences between family practices in the associations of patient characteristics with health care experiences. Medical Care Research and Review: 2011, 68(6), 725-739

\begin{tabular}{|l|l|}
\hline Postprint Version & 1.0 \\
\hline Journal website & http://mcr.sagepub.com/content/early/2011/04/19/1077558711405215.long \\
\hline Pubmed link & http://www.ncbi.nlm.nih.gov/pubmed/21536598 \\
\hline DOI & $10.1177 / 1077558711405215$ \\
\hline
\end{tabular}

This is a NIVEL certified Post Print, more info at http://www.nivel.eu

\title{
Differences Between Family Practices in the Associations of Patient Characteristics With Health Care Experiences
}

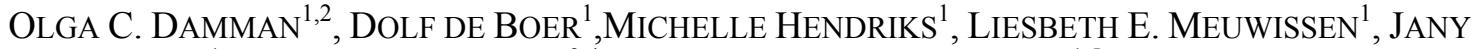 \\ RADEMAKERS ${ }^{1}$, DIANA M. J. DELNOIJ ${ }^{3,4}$ AND PETER P. GROENEWEGEN ${ }^{1,5}$ \\ ${ }^{1}$ NIVEL, Utrecht, the Netherlands \\ ${ }^{2}$ Department of Public and Occupational Health and the EMGO Institute for Health and Care Research, VU \\ University Medical Center, Amsterdam, the Netherlands \\ ${ }^{3}$ Centre for Consumer Experience in Healthcare, Utrecht, the Netherlands \\ ${ }^{4}$ TRANZO, Faculty of Social and Behavioural Sciences, Tilburg University, Tilburg, the Netherlands \\ 5Utrecht University, Department of Human Geography and Department of Sociology, Utrecht, the \\ Netherlands
}

\begin{abstract}
When comparing health care providers, patient experience data are usually adjusted for casemix associations to ensure fair comparisons. Previous studies in the United States showed that case-mix associations sometimes vary across health care providers. Such variation could indicate differential provider behavior for patient subgroups, in which case current adjustment techniques might be inappropriate. To see whether this variation is also apparent in a health care system different from the U.S. system, the authors analyzed Dutch patients' experiences with family practice care. Using multilevel random slope models, the associations between age, general health status, mental health status, education, sex, and ethnicity on one hand and reported experiences on the other hand were assessed across family practices. The authors found only five significant variances between case-mix coefficients, all for outcomes related to health care professionals' conduct. These findings correspond to previous U.S. findings, suggesting that the case-mix variations reported here and previously constitute a rather robust phenomenon.
\end{abstract}

\section{INTRODUCTION}

Patients' evaluations of health care quality have become a central part of performance measurement in many Western countries. Data collection typically generates a vast amount of quality information on a variety of aspects (e.g., health care professionals' conduct and communication, information provision, accessibility) and global evaluations of health care. To ensure fair comparisons of providers, it is recommended that ratings are adjusted for case-mix associations (Iezzoni, 1997; Welch, Black, \& Fisher, 1995). Ratings are usually adjusted for respondents' age, sex, health status, and education because these characteristics have been shown to be related to reported experiences (Huang et al., 2005; O'Malley, Zaslavsky, Elliott, Zaborski, \& Cleary, 2005; Zaslavsky et al., 2001). Although the size of case-mix 
associations is usually small (Damman et al., 2009; O’Malley et al., 2005), adjustment can make a difference for providers with atypical patient populations.

Case-mix associations are usually controlled for by multilevel regression models in which the associations are not allowed to vary across providers (in statistical terms - models with random intercepts and fixed effects for the covariates). Multilevel modeling is considered an appropriate method for analyzing institutional performance because it takes into account data clustering (patients within providers) and allows the estimation of between-provider variance (Arling, Lewis, Kane, Mueller, \& Flood, 2007; Christiansen \& Morris, 1997; Damman et al., 2009; Goldstein \& Spiegelhalter, 1996; Merlo, 2005; Zaslavsky, 2007). This method seems appropriate when patient characteristics reflect systematic response bias, such as when lower educated patients tend to rate their experiences more favorably than higher educated patients, or when real differences in health care experiences show similar patterns for different health care providers (Zaslavsky, Zaborski, \& Cleary, 2000).

However, U.S. studies of CAHPS data and other patient experience measures showed that patient subgroups' experiences sometimes vary across providers. Between-health plan and between-provider variability were demonstrated in the associations with age, health status, race/ethnicity, education, and language (Elliott et al., 2010; Elliott, Swartz, Adams, Spritzer, \& Hays, 2001; Lurie, Zhan, Sangl, Bierman, \& Sekscenski, 2003; Rodriguez, von Glahn, Grembowski, Rogers, \& Safran, 2008; Zaslavsky, Zaborski, \& Cleary, 2000). These patterns were mainly found for communication-related measures (Elliott et al., 2010; Rodriguez et al., 2008). In these cases, it is debatable whether ratings should be corrected as variability can imply differential provider behavior toward patient subgroups. As suggested by several researchers (Elliott et al., 2001; Elliott et al., 2010), performance information might be better presented for patient subgroups separately (also called stratified reports).

Given these arguments, it is necessary to check for between-provider variability in case-mix associations in patient experience measurements. In the Netherlands, such analyses have not yet been performed. It would be relevant to know whether the patterns demonstrated in the United States can be found for Dutch patients' experiences as well. The Dutch primary care system, the physician educational system, and the population are different from that of the United States, and these differences may result in different patientphysician relationships and different access to care. All noninstitutionalized inhabitants of the Netherlands are registered with a family practice, irrespective of whether they are ill or not. Dutch family practice care has no cost sharing, and the family physicians function as gatekeepers to specialist and hospital care. The Dutch system is thus characterized by continuous relationships with health care professionals in family practices and by easy and rapid access of care (Schoen, Osborn, How, Doty, \& Peugh, 2008). In addition, the Dutch family physician educational system is shorter and more uniform compared with the U.S. system. Besides this homogeneity of the health care system, the Dutch population is also more homogeneous (e.g., with regard to ethnicity) than the U.S. population. In terms of between provider variability of case-mix associations, one might expect more variability within the U.S. system.

\section{New Contribution}

The aim of the present work was to investigate the association between patient characteristics and reported health care experiences across different Dutch family practices. This is the first study that replicates and extends previously demonstrated variation in case-mix associations in the United States to a country with a different type of health care system and a more homogeneous population. Although multilevel models were applied in a study on case-mix associations in Dutch patient experience data (Damman et al., 2009), the variation of associations across providers remains to be determined.

\section{METHOD}

\section{Participants}

We used data from the CQI Family Practice Survey, which was disseminated among 11,637 people in 2007. These people were registered with a family practice. All the 11,637 people had at least one contact with their family physician during the past 12 months. We analyzed the experiences of 5,473 people within 32 family practices. 
Damman, O.C., Boer, D. de, Hendriks, M., Meuwissen, L.E., Rademakers, J., Delnoij, D.M.J., Groenewegen, P.P. Differences between family practices in the associations of patient characteristics with health care experiences. Medical Care Research and Review: 2011, 68(6), 725-739

The number of respondents per practice varied from 125 to 224 .

\section{Measurement}

The CQI Family Practice Survey was developed and tested in 2007 (Meuwissen \& De Bakker, 2008). The pilot questionnaire contained 82 items, of which 59 focused on patient experiences with health care provided by the family practice. Other questions were skip items ( 5 items), global ratings of the family practice (3 items), items on sociodemographic characteristics (10 items), items on patients' empowerment ( 3 items), 1 item about the family physician's sex, and 1 item assessing assistance with filling out the questionnaire.

\section{Statistical Analyses}

For the current analyses, we considered five outcome measures: four composite scores (different quality dimensions of family practice care) and one global rating (Table 1).

We analyzed the between-practice variability in case-mix associations by fitting random slope models, using multilevel linear regression analyses with random intercepts in MLwiN. These models (also called random effects models) allow the coefficients of independent variables to vary across providers (Rasbash, Steele, Browne, \& Prosser, 2004). We fitted models that included the following characteristics, commonly recognized as important case-mix adjusters (Eselius, Cleary, Zaslavsky, Huskamp, \& Busch, 2008; O’Malley et al., 2005; Zaslavsky, Hochheimer, et al., 2000): age, educational level, sex, self-reported general health status, self-reported mental health status, and ethnicity. First, we tested a model with random intercepts without case-mix variables (baseline model). Second, models including one case-mix variable each were fitted, with fixed slopes for the case-mix variables. Third, we allowed the slopes in the models to vary. To test the variability of case-mix associations, we assessed the variance of the slopes $(\sigma 2)$ in this third set of models.

To illustrate what stratified reports would look like in the event of heterogeneity across providers, we predicted practices' scores on the outcome "family physician's respectful treatment" for three standard values of the covariate "age": as if all respondents for all practices had an age of $x 1$, an age of $x 2$, or an age of x3. Scores were assessed using random slope models based on empirical Bayes's estimates. Each model resulted in mean scores with comparison intervals for each practice. We used the comparison intervals to create star ratings for the practices, reflecting relative performance (Goldstein \& Healy, 1995). Practices received 1 star (worse than average) when their comparison interval was below the overall mean score across all practices, 2 stars (average) when the interval overlapped the mean score, and 3 stars (better than average) when the interval was above the mean score. In MLwiN, provider scores and comparison intervals are by default calculated for the value 0 of the covariate. Instead of this, we used three standard values to create information for specific age categories. The calculations consisted of subtracting three different constants (a) from the covariate age $\left(\mathrm{x}^{\prime}=\mathrm{x}-\mathrm{a}\right)$, namely, the category levels corresponding to $\mathrm{a}=15$ to 25 years, $\mathrm{a}=46$ to 65 years, and $\mathrm{a}=75$ years and older (compare centering techniques; Enders $\&$ Tofighi, 2007).

\section{[TABLE 1]}

\section{RESULTS}

\section{Respondents' Characteristics}

Of all the respondents, $8 \%$ were younger than 25 years, $31 \%$ aged between 25 and 44 years, $37 \%$ between 45 and 64 years, $13 \%$ between 65 and 75 years, and $11 \%$ older than 75 years. More respondents were female (63\%) than male (37\%), and the majority had a Dutch background (82\%). Of the first and second generation immigrants, $11 \%$ were migrants from non-Western countries and $7 \%$ from Western countries. More than half (52\%) of the respondents had a low level of education, $29 \%$ an average level of education, and $19 \%$ were highly educated. Nearly $17 \%$ rated their health as very good or excellent, and nearly $30 \%$ gave this rating concerning their mental health. 
Damman, O.C., Boer, D. de, Hendriks, M., Meuwissen, L.E., Rademakers, J., Delnoij, D.M.J., Groenewegen, P.P. Differences between family practices in the associations of patient characteristics with health care experiences. Medical Care Research and Review: 2011, 68(6), 725-739

\section{Variability of Case-Mix Associations}

Significant variation between the slopes for different practices was found for age, education, general health status, and ethnicity on the outcomes "family physician's respectful treatment" and "communication with the practice assistant" (Tables 2 and 3).

No variation between slopes was found for the outcomes "tailored care," "accessibility of care," and "global rating for the family physician." Significant differences in the associations with age appeared for the respectful treatment by the family physician and communication with the practice assistant.

Significant variances for the other characteristics were only found for the family physician's respectful treatment. To illustrate the meaning of the significant slope variances, we also calculated the range of values of the average slopes \pm 2 standard deviations (Snijders \& Bosker, 1999). For respectful treatment by the family physician, these values varied from -0.0313 to 0.0890 for the covariate age, indicating a negative association for some practices, a positive association for others, and a $95 \%$ expected range of 0.1204 . The results for the other significant slope variances were broadly similar.

Figures 1 through 4 show the relationships between patient characteristics and experiences of the family physician's respectful treatment for the different practices in random slope models. As can be seen in Figure 1, the lines converge as age increases.

In other words, there are relatively large differences between practices for younger patients and relatively small differences for older patients. Furthermore, although age is positively related to experiences for most practices, some practices show a negative slope.

The slopes for most practices in the random slope model including education (Figure 2) are similar to slopes in the fixed effect model. For several practices, however, education shows a highly positive association and a highly negative association for others.

The graph of the random slopes for respondents' self-rated general health status (Figure 3 ) is similar to that for age (Figure 1), except that here all the slopes are positive.

The random slope model of the association between ethnicity and family physician's respectful treatment shows a diverging pattern (Figure 4), indicating larger differences between practices according to migrant patients than according to patients with an exclusively Dutch background.

\section{[TABLE 2,3] [FIGURE 1,2,3,4]}

\section{Case-Mix Variability and Performance Ratings}

In Table 4, the shifts in family practices' star ratings for the family physician's respectful treatment are displayed for two age categories in random slope models. The star ratings for these two categories are compared with that for the category of 15 to 25 year olds. Relatively large changes in star ratings occurred in the random slope model for age 75 and older. The pattern corresponds to Figure 1: There are relatively small differences between practices according to older patients, reflected by many shifts to an average performance.

\section{DISCUSSION}

The purpose of this study was to explore potential variability in case-mix associations with regard to patient experiences across Dutch family practices and to compare the results with previous U.S. findings. Using multilevel random effects analyses, we found little case-mix variability overall. However, some variability was found for the family physician's respectful treatment and communication with the practice assistant.

These findings are in line with U.S. studies (Elliott et al., 2010; Rodriguez et al., 2008). So despite the differences that exist between the two countries in terms of the population and the health care system, between-provider variability of case-mix associations mainly relate to conduct measures. These measures deal with how health care professionals behave and constitute key measures in patient experience research.

[TABLE 4] 


\section{Study Limitations}

With regard to patient experience data, the limited numbers of observations in several categories are a methodological problem. Relatively few young people and people reporting poor health filled out the questionnaire on patient experiences. The slopes of some practices are therefore based on a small number of observations. In addition, answers to some items of the composites were slightly skewed, with relatively few people reporting negative experiences. These methodological issues are not that important in the context of the current study because our aims were to explore and illustrate case-mix variability. In addition, the multilevel method used deals appropriately with small numbers of cases through "shrinkage" to the population mean (Snijders \& Bosker, 1999; Zaslavsky, 2001). Nevertheless, in the context of public performance data, these limitations should be carefully considered (Zaslavsky, 2001).

\section{Discussion of findings}

Significant variation between practices in case-mix associations was found for age, education, general health status, and ethnicity, which corresponds to findings from previous studies (Elliott et al., 2001; Elliott et al., 2010; Lurie et al., 2003; Rodriguez et al., 2008). The well-known response biases (older, healthy people born in the Netherlands and with lower levels of education reporting more positively) were not present for all practices, nor was the size of the associations consistent across practices.

These variations suggest that patient subpopulations as defined by age, educational level, health, and ethnicity may experience real differences in health care from different providers. Significant slope variances were found for themes related to health care professionals' conduct, such as listening carefully, treating the patient with respect, and spending enough time with the patient. This is also consistent with previous studies, in which variation in case-mix associations was mainly found for communication- related measures (Elliott et al., 2010; Rodriguez et al., 2008).

Considering our arguments about the differences between the American and the Dutch population and health care system, it is notable that most of our findings are in line with previous U.S. studies. It appears that the case-mix variations reported here and previously constitute a rather robust phenomenon regarding interpersonal communication that may also apply to other Western countries. This stresses the need for a debate about traditional case-mix corrections versus alternative adjustment strategies for conduct and communication measures. The variations reported are small but significant, and on the whole, performance ratings do not differ much whether using a model that allows case-mix variations or not. However, for the few individual providers that may score differently when using a model including case-mix variations, it may be a world of difference.

In our opinion, current adjustment techniques are appropriate for the majority of patient experiences and it is not necessary to provide information for specific subgroups of patients, perhaps with the exception of measures related to communication. However, it should be carefully checked per health care sector whether case-mix variations exist.

Where variable case-mix associations are found, researchers could also consider a completely different method for case-mix adjustment, namely, the use of more direct measures of systematic response bias than patient characteristics. For example, the use of anchoring vignettes to identify reporting tendencies might be an alternative. Patient experiences are then analyzed using regression models with corrections for patients' responses to vignettes (King, Murray, Salomon, \& Tandon, 2004). The advantage is that systematic response bias is filtered out, while real differences remain intact. More research is needed to assess the methodological benefits and practical implementation of this approach. Knowledge development in such case-mix adjustment techniques should be exchanged between different countries.

\section{DECLARATION OF CONFLICTING INTERESTS}

The author(s) declared no potential conflicts of interest with respect to the research, authorship, and/or publication of this article.

\section{FUNDING}

The author(s) received no financial support for the research, authorship, and/or publication of this article. 
Damman, O.C., Boer, D. de, Hendriks, M., Meuwissen, L.E., Rademakers, J., Delnoij, D.M.J., Groenewegen, P.P. Differences between family practices in the associations of patient characteristics with health care experiences. Medical Care Research and Review: 2011, 68(6), 725-739

\section{REFERENCES}

Arling, G., Lewis, T., Kane, R. L., Mueller, C., \& Flood, S. (2007). Improving quality assessment through multilevel modelling: The case of nursing home compare. Health Services

Research, 42, 1177-1199.

Christiansen, C. L., \& Morris, C. N. (1997). Improving the statistical approach to healthcare provider profiling. Annals of Internal Medicine, 127, 764-768.

Damman, O. C., Stubbe, J. H., Hendriks, M., Arah, O. A., Spreeuwenberg, P., Delnoij, D. M., . . . Groenewegen, P. P. (2009). Using multilevel modeling to assess case-mix adjusters in consumer experience surveys in health care. Medical Care, 47, 496-503.

Elliott, M. N., Lehrman, W. G., Goldstein, E., Hambarsoomian, K., Beckett, M. K., \& Giordano, L. A. (2010). Do hospitals rank differently on HCAHPS for different patient subgroups? Medical Care Research and Review, 76, 56-73.

Elliott, M. N., Swartz, R., Adams, J., Spritzer, K. L., \& Hays, E. D. (2001). Case-mix adjustment of the national CAHPS benchmarking data 1.0: A violation of model assumptions? Health Services Research, 36, 555-573.

Enders, C. K., \& Tofighi, D. (2007). Centering predictor variables in cross-sectional multilevel models: A new look at an old issue. Psychological Methods, 12, 121-138.

Eselius, L. L., Cleary, P. D., Zaslavsky, A. M., Huskamp, H. A., \& Busch, S. H. (2008). Case-mix adjustment of consumer reports about managed behavioral health care and health plans.

Health Services Research, 43, 2014-2032.

Goldstein, H., \& Healy, M. J. R. (1995). The graphical presentation of a collection of means.

Journal of the Royal Statistical Society. Series A (Statistics in Society), 158, 175-177.

Goldstein, H., \& Spiegelhalter, D. J. (1996). League tables and their limitations: Statistical issues in comparisons of institutional performance. Journal of the Royal Statistical Society.

Series A (Statistics in Society), 159, 385-443.

Huang, I. C., Dominici, F., Frangakis, C., Diette, G. B., Damberg, C. L., \& Wu, A. W. (2005).

Is risk-adjustor selection more important than statistical approach for provider profiling? Asthma as an example. Medical Decision Making, 25, 20-34.

Iezzoni, L. I. (1997). Risk adjustment for measuring healthcare outcomes. Chicago, IL: Health Administration Press.

King, G., Murray, C. J. L., Salomon, J. A., \& Tandon, A. (2004). Enhancing the validity and cross-cultural comparability of measurement in survey research. American Political Science

Review, 97, 567-584.

Lurie, N., Zhan, C., Sangl, J., Bierman, A. S., \& Sekscenski, E. S. (2003). Variation in racial and ethnic differences in consumer assessments of health care. American Journal of Managed

Care, 9, 502-509.

Merlo, J. (2005). Changing analytical approaches in European epidemiology—A short comment on a recent article. European Journal of Epidemiology, 20, 737.

Meuwissen, L. E., \& De Bakker, D. H. (2008). CQ-index huisartsenzorg: Meetinstrumentontwikkeling.

Kwaliteit van de zorg in de huisartsenpraktijk vanuit het perspectief van

patiënten [CQ-general practice care: Development of a questionnaire. Quality of general practice care through the patient's eye]. Utrecht, Netherlands: NIVEL (Netherlands Institute for Health Services Research).

O'Malley, A. J., Zaslavsky, A. M., Elliott, M. N., Zaborski, L., \& Cleary, P. D. (2005). Casemix adjustment of the CAHPS $\AA$ Hospital Survey. Health Services Research, 40, 2162-2181.

Rasbash, J., Steele, F., Browne, W., \& Prosser, B. (2004). A user's guide to MLwiN version 2.0.

London, England: Institute of Education, University of London.

Rodriguez, H. P., von Glahn, T., Grembowski, D. E., Rogers, W. H., \& Safran, D. G. (2008).

Physician effects on racial and ethnic disparities in patients' experiences of primary care.

Journal of General Internal Medicine, 23, 1666-1672.

Schoen, C., Osborn, R., How, S. K. H., Doty, M. M., \& Peugh, J. (2008, November 13). In chronic condition: Experiences of patients with complex health care needs, in eight countries, 2008. Health Affairs, Web Exclusive, w1-w16.

Snijders, T. A. B., \& Bosker, R. J. (1999). Multilevel analysis: An introduction to basic and advanced multilevel modeling. Thousand Oaks, CA: Sage.

Welch, H. G., Black, W. C., \& Fisher, E. S. (1995). Case-mix adjustment: Making bad apples look good. Journal of the American Medical Association, 273, 772-773.

Zaslavsky, A. M. (2001). Statistical issues in reporting quality data: Small samples and casemix variation. International Journal for Quality in Health Care, 13, 481-488. 
Damman, O.C., Boer, D. de, Hendriks, M., Meuwissen, L.E., Rademakers, J., Delnoij, D.M.J., Groenewegen, P.P. Differences between family practices in the associations of patient characteristics with health care experiences. Medical Care Research and Review: 2011, 68(6), 725-739

Zaslavsky, A. M. (2007). Using hierarchical models to attribute sources of variation in consumer assessments of healthcare. Statistics in Medicine, 26, 1885-1900.

Zaslavsky, A. M., Hochheimer, J. N., Schneider, E. C., Cleary, P. D., Seidman, J. J., McGlynn, E. A., . . . Epstein, A. M. (2000). Impact of sociodemographic case mix on the HEDIS measures of health plan quality. Medical Care, 38, 981-992.

Zaslavsky, A. M., Zaborski, L., \& Cleary, P. D. (2000). Does the effect of respondent characteristics on consumer assessments vary across health plans? Medical Care Research and

Review, 57, 379-394.

Zaslavsky, A. M., Zaborski, L. B., Ding, L., Shaul, J. A., Cioffi, M. J., \& Cleary, P. D. (2001).

Adjusting performance measures to ensure equitable plan comparisons. Health Care Financing Review, 22(3), 109-126. 
Damman, O.C., Boer, D. de, Hendriks, M., Meuwissen, L.E., Rademakers, J., Delnoij, D.M.J., Groenewegen, P.P. Differences between family practices in the associations of patient characteristics with health care experiences. Medical Care Research and Review: 2011, 68(6), 725-739

[TABLES AND FIGURES]

Table I. Outcome Measures

\begin{tabular}{|c|c|c|c|c|}
\hline Variable & $\begin{array}{l}\text { Number } \\
\text { of Items }\end{array}$ & Items & $\begin{array}{l}\text { Response } \\
\text { Categories }\end{array}$ & $\begin{array}{c}\text { Cronbach's } \\
\alpha\end{array}$ \\
\hline $\begin{array}{l}\text { Family physician's } \\
\text { respectful } \\
\text { treatment }\end{array}$ & 4 & $\begin{array}{l}\text { How often did your doctor } \\
\text { listen carefully to you? } \\
\text { How often did your doctor treat } \\
\text { you seriously? } \\
\text { How often did your doctor treat } \\
\text { you with respect? } \\
\text { How often did your doctor } \\
\text { spend enough time with you? }\end{array}$ & $\begin{array}{l}\text { Never (I); } \\
\text { sometimes (2); } \\
\text { usually (3); } \\
\text { always (4) }\end{array}$ & .85 \\
\hline $\begin{array}{l}\text { Practice assistant's } \\
\text { communication }^{\mathrm{a}}\end{array}$ & 6 & $\begin{array}{l}\text { How often were the doctors } \\
\text { and other practice staff ready } \\
\text { to help? } \\
\text { When you phoned the family } \\
\text { practice during regular office } \\
\text { hours, how often did you get } \\
\text { the help you needed? } \\
\text { How often was it a problem } \\
\text { for you to tell your story to } \\
\text { the practice assistant, before } \\
\text { you could speak to the } \\
\text { doctor? } \\
\text { How often did the practice } \\
\text { assistant rightly decided that } \\
\text { you needed an appointment } \\
\text { with the doctor? } \\
\text { How often did the practice } \\
\text { assistant treat you with } \\
\text { respect? } \\
\text { How often did the practice } \\
\text { assistant spend enough time } \\
\text { with you? }\end{array}$ & $\begin{array}{l}\text { Never (I); } \\
\text { sometimes (2); } \\
\text { usually (3); } \\
\text { always (4) }\end{array}$ & .75 \\
\hline Tailored care & 9 & $\begin{array}{l}\text { How often were you informed } \\
\text { about different treatment } \\
\text { options? } \\
\text { How often did you get the } \\
\text { chance to decide about your } \\
\text { treatment? } \\
\text { How often did the doctor } \\
\text { describe possible side effects } \\
\text { of prescribed medicine? } \\
\text { How often did the doctor } \\
\text { explain why it was important } \\
\text { to follow his or her } \\
\text { instructions or advice? }\end{array}$ & $\begin{array}{l}\text { Never (I); } \\
\text { sometimes (2); } \\
\text { usually (3); } \\
\text { always (4) }\end{array}$ & .88 \\
\hline
\end{tabular}


Damman, O.C., Boer, D. de, Hendriks, M., Meuwissen, L.E., Rademakers, J., Delnoij, D.M.J., Groenewegen, P.P. Differences between family practices in the associations of patient characteristics with health care experiences. Medical Care Research and Review: 2011, 68(6), 725-739

Table I. (continued)

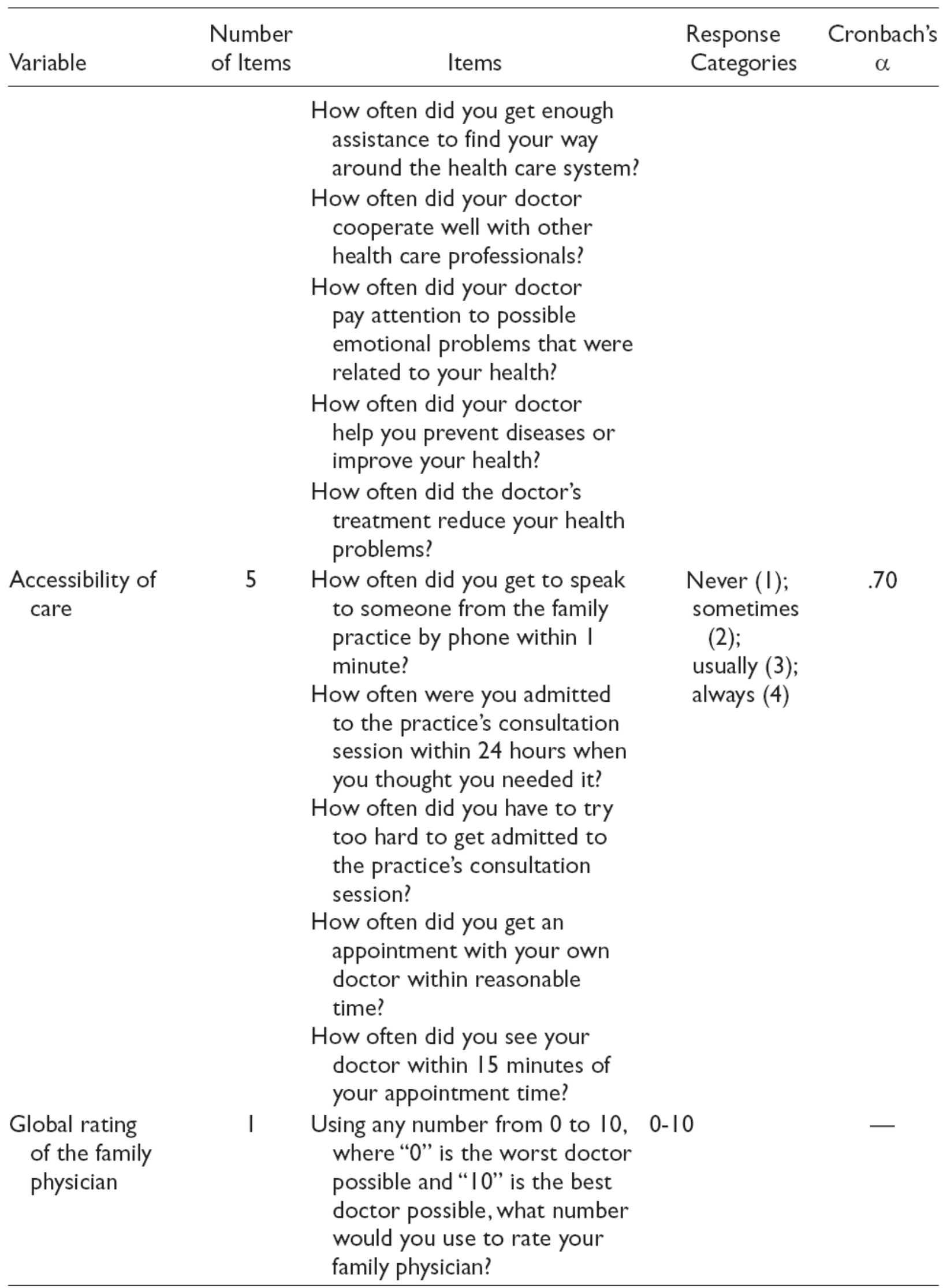

a. The profession of practice assistant is a profession closely related to that of a practice secretary or a practice nurse. 
Damman, O.C., Boer, D. de, Hendriks, M., Meuwissen, L.E., Rademakers, J., Delnoij, D.M.J., Groenewegen, P.P. Differences between family practices in the associations of patient characteristics with health care experiences. Medical Care Research and Review: 2011, 68(6), 725-739

Table 2. Random Effects of Case-Mix Adjusters Compared With Fixed Effects for the Family Physician's Respectful Treatment

\begin{tabular}{|c|c|c|c|c|c|}
\hline & Intercept & $\begin{array}{c}\beta \text { Case-Mix } \\
\text { Adjuster }\end{array}$ & $\begin{array}{c}\sigma^{2} \text { Case-Mix } \\
\text { Adjuster }\end{array}$ & $I C C^{a}$ & $\chi^{2 b}$ \\
\hline Baseline model & $3.7637(0.0174)^{*}$ & - & - & 0.047 & - \\
\hline Age Model a & $3.6369(0.0299)^{*}$ & $.0261(.0050)^{*}$ & - & 0.046 & $26.819 *$ \\
\hline Age Model b & $3.6255(0.0460)^{*}$ & $.0289(.0074)^{*}$ & $.0009(.0004)^{*}$ & 0.215 & $17.954 *$ \\
\hline $\begin{array}{l}\text { Education } \\
\text { Model a }\end{array}$ & $3.7616(0.0212)^{*}$ & $.0006(.0035)$ & - & 0.047 & 0.330 \\
\hline $\begin{array}{l}\text { Education } \\
\text { Model b }\end{array}$ & $3.7643(0.0250)^{*}$ & $-.0000(.005 \mathrm{I})$ & $.0004(.0002)^{*}$ & 0.076 & $10.506 *$ \\
\hline Male Model $a^{c}$ & $3.7309(0.0238)^{*}$ & $.0241(.0118)^{*}$ & - & 0.048 & $4.144 *$ \\
\hline Male Model $b^{c}$ & $3.7309(0.0238)^{*}$ & $.0241(.0118)^{*}$ & $.0000(.0000)$ & 0.048 & 0.000 \\
\hline Health Model a & $3.5405(0.0267)^{*}$ & $.0758(.0069)^{*}$ & - & 0.046 & $118.299 *$ \\
\hline Health Model b & $3.5375(0.0396)^{*}$ & $.077 \mid(.0097)^{*}$ & $.0014(.0007)^{*}$ & 0.174 & $18.076 *$ \\
\hline $\begin{array}{l}\text { Mental health } \\
\text { Model a }\end{array}$ & $3.5756(0.0263)^{*}$ & $.0583(.0063)^{*}$ & - & 0.047 & $86.036 *$ \\
\hline $\begin{array}{l}\text { Mental health } \\
\text { Model b }\end{array}$ & $3.5750(0.0350)^{*}$ & $.0584(.0082)^{*}$ & $.0009(.0005)$ & 0.128 & $8.254 *$ \\
\hline $\begin{array}{l}\text { Migrant } \\
\text { Model a }\end{array}$ & $3.9496(0.0246)^{*}$ & $-.1557(.0159)^{*}$ & - & 0.038 & 94.374 \\
\hline $\begin{array}{l}\text { Migrant } \\
\text { Model b }\end{array}$ & $3.9445(0.0207)^{*}$ & $-.1493(.0210)^{*}$ & $.0048(.0014)^{*}$ & 0.00 & $18.830 *$ \\
\hline
\end{tabular}

Note. $N=5,47$; the models include one case-mix adjuster each.The "a" models are the models with random intercepts and fixed effects of the case-mix adjusters. The "b" models are the models with random intercepts and random effects of the case-mix adjusters. $\Delta d f$ is I in each model following the baseline model. Age, education, and the health variables were measured as categorical variables in the questionnaire. They were included as if they were continuous variables in the current analyses, to facilitate interpretation of the results. Preliminary analyses—not shown here - showed that specifying the variables as continuous accounted for a similar amount of variance as categorical specifications, which is in line with previous patient experience studies. $\beta=$ regression coefficient; $\sigma^{2}=$ variation in the slopes across the family practices' summary lines.

a. $I C C=$ intraclass correlation $=$ Var providers $/($ Var providers + Var consumers $)$.

b. Changes in -2 log likelihood were calculated; significance testing with chi-square:"a" models compared with the baseline model and "b" models compared with the "a" models.

c. Sex was coded as female (0) or male (I).

d. Ethnicity was coded as exclusively Dutch (0) or migrant (I). The group of migrants consisted of both Western and non-Western migrants.

$* p<.05$.

Boldface is used to indicate the significant slope variance. 
Damman, O.C., Boer, D. de, Hendriks, M., Meuwissen, L.E., Rademakers, J., Delnoij, D.M.J., Groenewegen, P.P. Differences between family practices in the associations of patient characteristics with health care experiences. Medical Care Research and Review: 2011, 68(6), 725-739

Table 3. Random Effects of Case-Mix Adjusters Compared With Fixed Effects for the Practice Assistant's Communication

\begin{tabular}{|c|c|c|c|c|c|}
\hline & Intercept & $\begin{array}{c}\beta \text { Case-Mix } \\
\text { Adjuster }\end{array}$ & $\begin{array}{c}\sigma^{2} \text { Case-Mix } \\
\text { Adjuster }\end{array}$ & $I C C^{a}$ & $\chi^{2 b}$ \\
\hline Baseline model & $3.4882(0.0254)^{*}$ & - & - & 0.077 & - \\
\hline Age Model a & $3.255 \mathrm{I}(0.0377)^{*}$ & $.048 \mid(.0058)^{*}$ & - & 0.076 & $68.132^{*}$ \\
\hline Age Model b & $3.2428(0.0600)^{*}$ & $.0510(.0086)^{*}$ & $.0013(.0006)^{*}$ & 0.280 & $25.326 *$ \\
\hline Education Model a & $3.4316(0.0286)^{*}$ & $.0163(.0041)^{*}$ & - & 0.074 & $16.217^{*}$ \\
\hline Education Model b & $3.4333(0.0318)^{*}$ & $.0160(.0050)^{*}$ & $.0003(.0002)$ & 0.097 & 3.774 \\
\hline Male Model $a^{c}$ & $3.4997(0.0315)^{*}$ & $-.0084(.0137)$ & - & 0.077 & 0.375 \\
\hline Male Model $b^{c}$ & $3.4993(0.0329)^{*}$ & $-.008 \mid(.0 \mid 45)$ & .0007 (.0017) & 0.087 & 0.281 \\
\hline Health Model a & $3.2854(0.0343)^{*}$ & $.0689(.008 \mathrm{I})^{*}$ & - & 0.074 & $72.66 I^{*}$ \\
\hline Health Model b & $3.2846(0.0444)^{*}$ & $.0694(.0105)^{*}$ & .0014 (.0009) & 0.160 & $7.309 *$ \\
\hline $\begin{array}{l}\text { Mental health } \\
\text { Model a }\end{array}$ & $3.3330(0.0342)^{*}$ & $.048 \mid(.0073)^{*}$ & - & 0.074 & $43.688^{*}$ \\
\hline $\begin{array}{l}\text { Mental health } \\
\text { Model b }\end{array}$ & $3.3329(0.0347)^{*}$ & $.0480(.0082)^{*}$ & $.0005(.0005)$ & 0.079 & 1.285 \\
\hline Migrant Model $a^{d}$ & $3.8223(0.0307)^{*}$ & $-.2798(.0182)^{*}$ & - & 0.058 & $229.555^{*}$ \\
\hline Migrant Model b & $3.8217(0.0309)^{*}$ & $-.2776(.0251)^{*}$ & .0077 (.0047) & 0.053 & $8.428 *$ \\
\hline
\end{tabular}

Note. $N=5,462$; the models include one case-mix adjuster each. The "a" models are the models with random intercepts and fixed effects of the case-mix adjusters. The "b" models are the models with random intercepts and random effects of the case-mix adjusters. $\Delta d f$ is I in each model following the baseline model. Age, education, and the health variables were measured as categorical variables in the questionnaire. They were included as if they were continuous variables in the current analyses, to facilitate interpretation of the results. Preliminary analyses—not shown here-showed that specifying the variables as continuous accounted for a similar amount of variance as categorical specifications, which is in line with previous patient experience studies. $\beta=$ regression coefficient; $\sigma^{2}=$ variation in the slopes across the family practices' summary lines.

a. ICC $=$ intraclass correlation $=$ Var providers/(Var providers + Var consumers).

b. Changes in -2 log likelihood were calculated; significance testing with chi-square: "a" models compared with the baseline model and "b" models compared with the "a" models.

c. Sex was coded as female (0) or male (I).

d. Ethnicity was coded as exclusively Dutch (0) or migrant (I). The group of migrants consisted of both Western and non-Western migrants.

$* p<.05$.

Boldface is used to indicate the significant slope variance. 
Damman, O.C., Boer, D. de, Hendriks, M., Meuwissen, L.E., Rademakers, J., Delnoij, D.M.J., Groenewegen, P.P. Differences between family practices in the associations of patient characteristics with health care experiences. Medical Care Research and Review: 2011, 68(6), 725-739

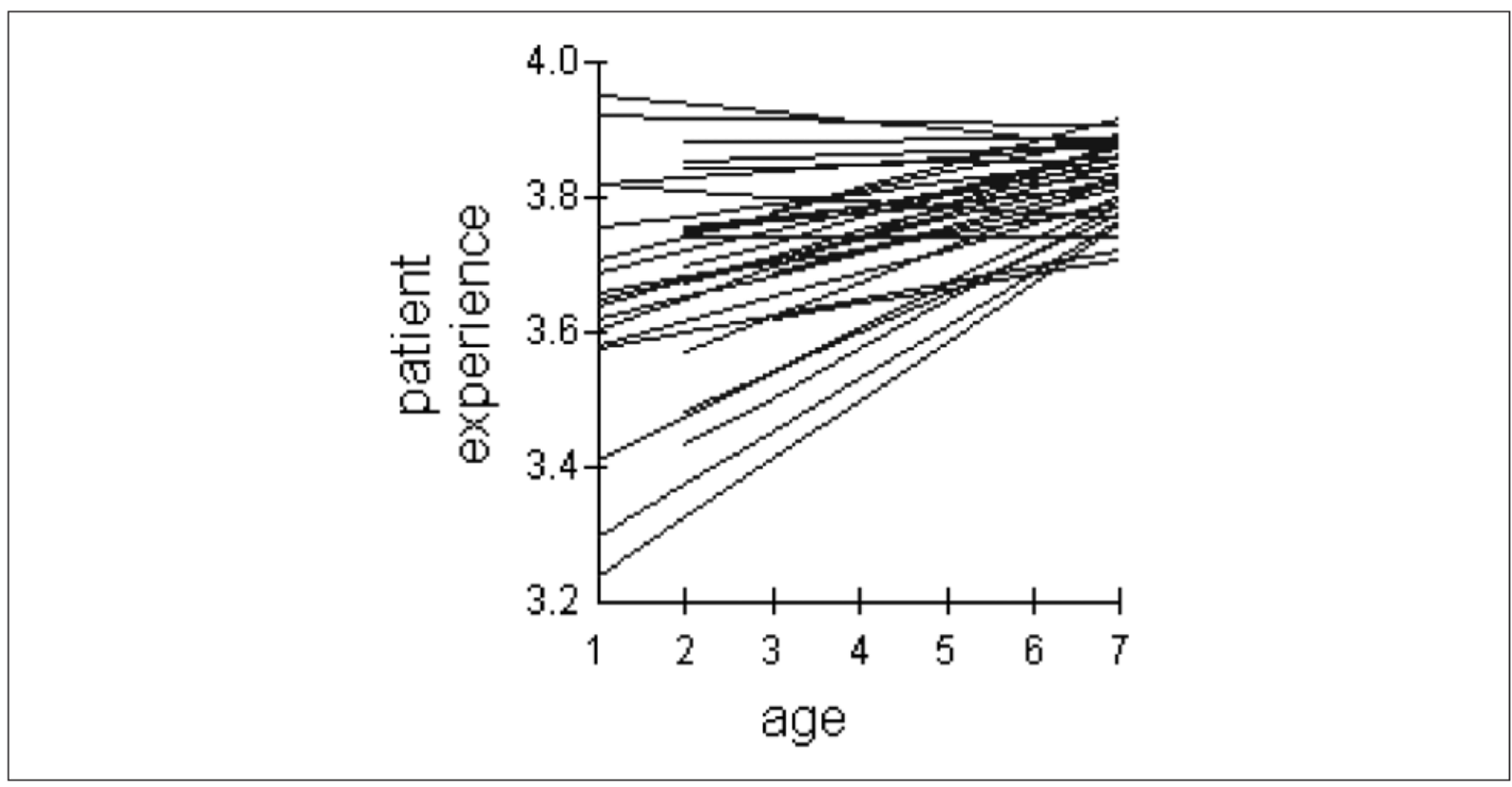

Figure I. The association between respondents' age and experiences with the family physician's respectful treatment: model with random effect of ageNote. Each line corresponds to one practice; the higher the patient experience, the more positive.

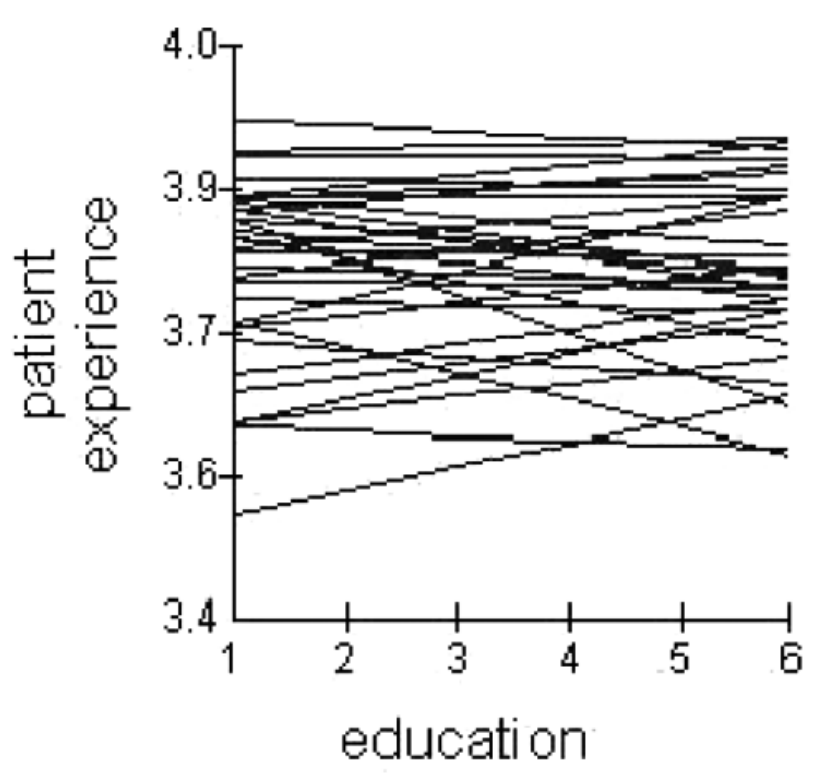

Figure 2. The association between respondents' education and experiences with the family physician's respectful treatment: model with random effect of educationNote. Each line corresponds to one practice; the higher the patient experience, the more positive. 
Damman, O.C., Boer, D. de, Hendriks, M., Meuwissen, L.E., Rademakers, J., Delnoij, D.M.J., Groenewegen, P.P. Differences between family practices in the associations of patient characteristics with health care experiences. Medical Care Research and Review: 2011, 68(6), 725-739

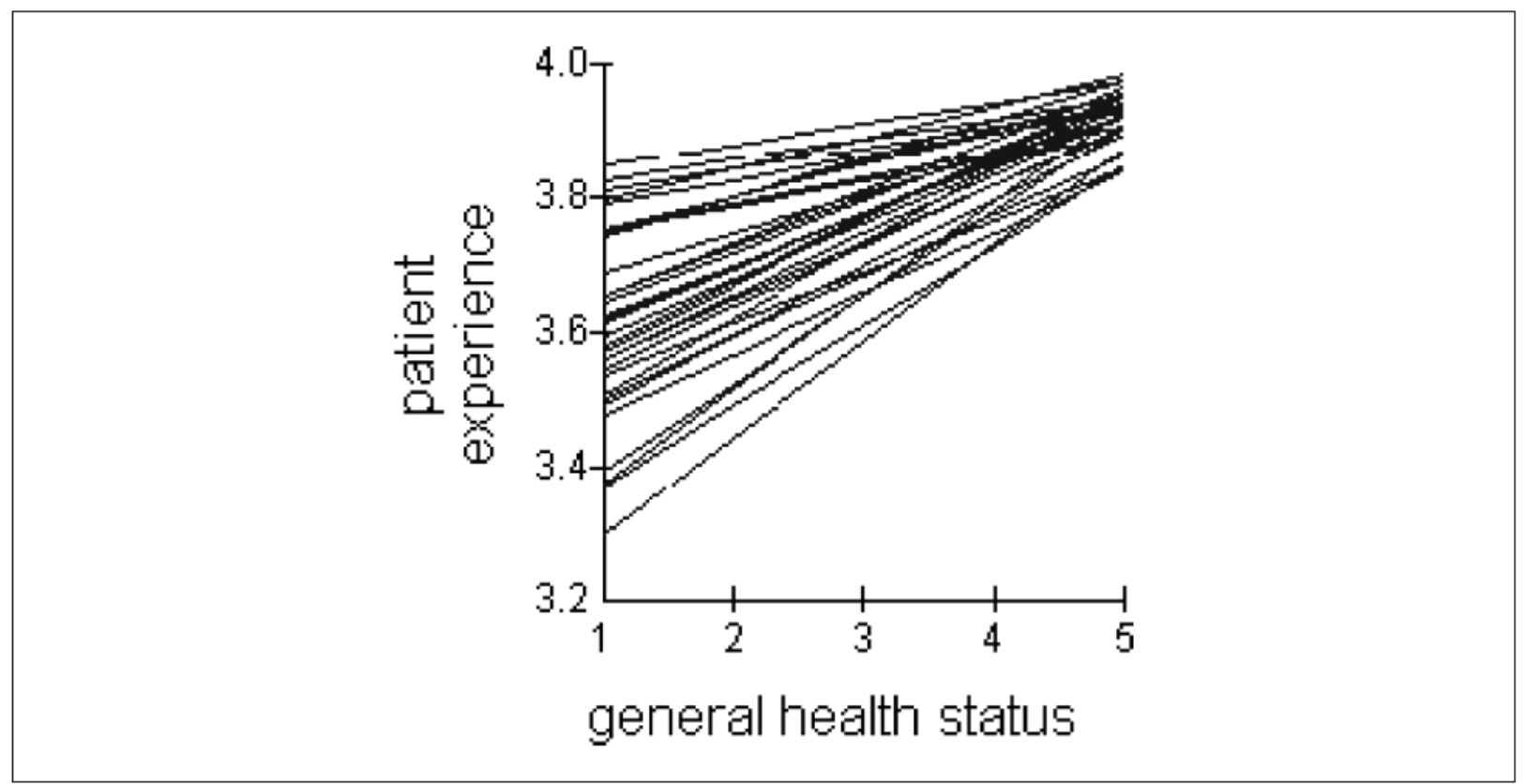

Figure 3. The association between respondents' general health status and experiences with the family physician's respectful treatment: model with random effect of health statusNote. Each line corresponds to one practice; the higher the patient experience, the more positive.

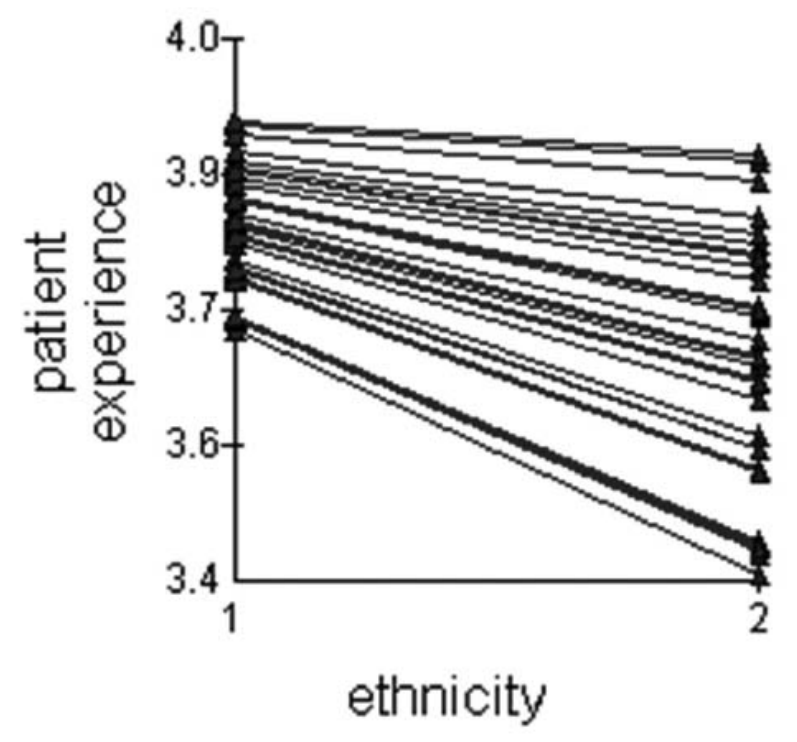

Figure 4. The association between respondents' ethnicity and experiences with the family physician's respectful treatment: model with random effect of ethnicityNote. Each line corresponds to one practice; the higher the patient experience, the more positive. 
Damman, O.C., Boer, D. de, Hendriks, M., Meuwissen, L.E., Rademakers, J., Delnoij, D.M.J., Groenewegen, P.P. Differences between family practices in the associations of patient characteristics with health care experiences. Medical Care Research and Review: 2011, 68(6), 725-739

Table 4. Changes in Star Ratings for the Family Physician's Respectful Treatment

\begin{tabular}{lcc}
\hline & $\begin{array}{c}\text { Model With Reference Value of } \\
46-65 \text { Years }\end{array}$ & $\begin{array}{c}\text { Model With Reference Value of } \\
\text { 75 Years and Older }\end{array}$ \\
\hline I Star remains I star & 7 & 3 \\
2 Stars remain 2 stars & 13 & 13 \\
3 Stars remain 3 stars & 7 & 1 \\
I Star becomes 2 stars & 1 & 5 \\
I Star becomes 3 stars & - & 1 \\
2 Stars become I star & I & 2 \\
2 Stars become 3 stars & 2 & 6 \\
3 Stars become 2 stars & I & 1 \\
3 Stars become I star & - &
\end{tabular}

Note. The changes in star ratings are the changes in the random slope models with different reference values for age compared with the model with a reference value of 15 to 25 years. 